\title{
Amphotericin B lipid complex: treatment of invasive fungal infections in patients refractory to or intolerant of amphotericin B deoxycholate
}

\author{
$\mathrm{PH}$ Chandrasekar \\ Division of Infectious Diseases, \\ Department of Internal Medicine, \\ Wayne State University, Karmanos \\ Cancer Institute, Detroit, MI, USA
}

Correspondence: PH Chandrasekar Harper University Hospital, 3990 John R, Detroit, MI 4820I, USA $\mathrm{Tel}+$ I 3137959649

$\mathrm{Fax}+$ I 3139930302

Email pchandrasekar@med.wayne.edu

\begin{abstract}
Amphotericin B lipid complex (ABLC) was introduced in the late 1990s as a less toxic alternative to amphotericin $\mathrm{B}(\mathrm{AmB})$ deoxycholate. ABLC is a safe and effective broad-spectrum drug in the treatment of invasive fungal infections in patients with infection refractory to $\mathrm{AmB}$ deoxycholate or in patients intolerant of the same formulation. The drug has not been rigorously evaluated for primary therapy. Recent availability of several newer potent and safe drugs has sharply curtailed the use of potentially nephrotoxic ABLC. However, AmB lipid complex is likely to continue to play a limited albeit significant clinical role in view of the narrow spectrum of activity and significant drug-drug interactions of the newer drugs and emergence of drug-resistant fungi.
\end{abstract}

Keywords: amphotericin B lipid complex, invasive fungal infections

\section{Introduction}

Incidence of invasive fungal infections is steadily on the rise over the past few decades, mainly due to an increase in the number of immunocompromised hosts, increasing number of older patients, and a sharp increase in the use of vascular and other devices (Ostrosky-Zeichner and Pappas 2006; Chamilos et al 2006; Martin et al 2003). Such infections, in the setting of compromised host defenses, are associated with considerable morbidity and mortality. Until 2 decades ago, amphotercin B (AmB) deoxycholate (a polyene) and narrow-spectrum flucytosine were the only available systemic antifungal drugs; serious nephrotoxicity associated with AmB has long hampered its liberal use. Arrival of a safer class of drugs, triazoles, particularly fluconazole, made an enormous impact in the outcome of patients with systemic candidiasis. In the late 1990s, almost 40 years after the introduction of AmB deoxycholate, three lipid-based AmB formulations, namely AmB lipid complex (ABLC), AmB colloidal dispersion $(\mathrm{ABCD})$ and liposomal AmB were developed to reduce nephrotoxicity without compromising efficacy. Additionally, within the past decade, newer triazoles (voriconazole, posaconazole) and echinocandins (caspofungin, micafungin, and anidulafungin) have become available, thus now providing several choices to the clinician.

Availability of a large number of antifungal drugs within a relatively short period has led to clinical dilemmas regarding the appropriate uses of 'newer', as well as 'older' drugs. This review focuses on the data on the efficacy and safety of AmB lipid complex and highlights the role of polyenes in the current clinical scene of changing fungal epidemiology, emergence of antifungal resistance, and expanding at-risk populations.

AmB remains the antifungal drug with the broadest spectrum of activity, effective against almost all clinically relevant yeasts and molds. Exceptions to the rule 
include Candida lusitaniae (about 20\% resistance), Candida guilliermondi (Hawkins and Baddour 2003), Aspergillus terreus (Sutton et al 1999), and Scedosporium species (Gilgado et al 2006). All 3 lipid forms of AmB exhibit similar spectrum of activity in vitro.

ABLC consists of AmB complexed with 2 phospholipids in a 1:1 drug to lipid molar ratio. The 2 phospholipids L- $\alpha$-dimyristoylphosphatidyl choline (DMPC) and L- $\alpha$-dimyristoyl phosphatidylglycerol (DMPG) are present in a 7:3 molar ratio (Janoff et al 1993). ABLC is characterized by lipid stabilized AmB aggregates appearing as ribbon-like structures. After iv administration, ABLC is rapidly cleared from the blood, and high concentrations are sequestered in the reticuloendothelial tissues in the liver, spleen, and lung (Adedoyin et al 1997). At the infected tissue sites, AmB is thought to be selectively released from the lipid complex by the fungal lipases. The 3 lipid forms of AmB have distinct pharmacological profiles. For example, in the immunocompromised mouse model of invasive pulmonary-aspergillosis, ABLC $(5 \mathrm{mg} / \mathrm{kg} / \mathrm{d})$ produced a more rapid fungal clearance than liposomal AmB (5 mg/kg/d) suggesting that ABLC may deliver active amphotericin to the lung more rapidly than liposomal AmB (Lewis et al 2007).

ABLC is US FDA approved for use as second-line therapy for the treatment of systemic fungal infections in patients who are refractory to or intolerant of conventional AmB or other systemic antifunal agents, have renal impairment or other contraindications to $\mathrm{AmB}$, or have developed AmB nephrotoxicity. Most of the studies with ABLC were conducted during the 1990s, and hence comparative data with the newer triazoles and echinocandins are not available. Such comparative studies are unlikely to be performed. The dose recommended for use is $5 \mathrm{mg} / \mathrm{kg} / \mathrm{d}$, given as a single iv infusion, for all patients including those with liver or renal disease.

Data leading to the US FDA approval for clinical use of ABLC were derived from 556 cases of invasive fungal infections collected through an open-label, single-patient, emergency-use study of patients who were refractory to or intolerant of antifungal therapy (Walsh et al 1998). Most of these patients had received prior AmB deoxycholate. A second major data source is the industry supported CLEAR (Collaborative Exchange of Antifungal Research) registry which provides data on the efficacy and renal safety of ABLC from data on 3514 patients who had received the drug during 1996 to 2000 at $>160$ North American institutions (Pappas 2005) (Table 1). These registry data have many limitations: the registry is retrospective; data collection was based on
Table I Demographic characteristics of all patients registered in the Collaborative Exchange of Antifungal Research (CLEAR) database $(\mathrm{N}=35 \mid 4)$

\begin{tabular}{ll}
\hline Characteristic & Value \\
\hline Age, median (range), years & $46(<\mathrm{I}-97)$ \\
Sex & \\
Male & $2039(58)$ \\
Female & $1466(42)$ \\
Unknown & $9(<\mathrm{I})$ \\
Reason for starting therapy with ABLC & \\
Refractory to prior antifungals & $14 \mathrm{II}(40)$ \\
Underlying renal disease and prior antifungal & $84(2)$ \\
Underlying renal disease and no prior antifungal & $945(27)$ \\
Intolerant of prior antifungals & $573(16)$ \\
No prior antifungal/no renal disease & $43 \mathrm{I}(\mathrm{I})$ \\
First-line therapy with ABLC & $1376(39)$ \\
Unknown & $57(2)$ \\
Other & $13(<\mathrm{I})$ \\
Underlying medical conditions and procedures & \\
Hematologic disorders & \\
Leukemia & \\
Lymphoma &
\end{tabular}

Note: Data are no. (\%) of patients, except where noted. Patients may have had $>$ I primary underlying condition.

aFirst-line therapy was defined as categories of no prior antifungal/no renal disease or underlying renal disease with no prior antifungal.

Abbreviations: ABLC, amphotericin B lipid complex; BMT, bone-marrow transplantation; GVHD, graft-versus-host disease; PSCT, peripheral stem-cell transplantation.

Adapted with permission from Pappas PG (ed). 2005. Amphotericin B lipid complex in the treatment of invasive fungal infections: results of the Collaborative Exchange of Antifungal Research (CLEAR), an industry-supported patient registry. Clin Infect Dis, 40(Suppl 6): S379-S83. Copyright @ 2005. University of Chicago Press. All rights reserved.

voluntary reporting with possible selection bias; objectively defined response criteria were lacking; and follow-up of patients was limited. The present review is largely based on the data from the above 2 sources, combined with available recent data (2003-2007). 


\section{Invasive candidiasis/candidemia}

In the emergency-use study, the overall response rate for patients with candidiasis $(n=91)$ was $71 \%$ (Walsh et al 1998). Responses were: $67 \%$ in disseminated candidiasis $(\mathrm{n}=42) ; 75 \%$ in fungemia $(\mathrm{n}=20)$; and $76 \%$ in single-organ candidiasis $(n=20)$. No difference in therapeutic responses was noted for the different candida species. In the large collaborative exchange of antifungal research (CLEAR) cohort registry, ABLC achieved 61\% response ( cured or/ improved) rate in 920 patients infected (invasive or noninvasive) with candida species; clinical responses were similar in patients infected with $\mathrm{C}$. albicans and non-albicans candida species (Ito and Hooshmand-Rad 2005) . Greater than 60\% response rate was documented in patients infected with either Candida krusei or Candida glabrata (Table 2). Response rates to C. Iusitaniae and C. guilliermondii were 56\% (5 of 9 cases) and $33 \%$ (2 of 6 csaes), respectively. In a small $(n=74)$ Spanish cohort of patients with hematologic malignancies, complete/partial response was noted in 6 of 11 patients with invasive candidiasis; ABLC, administered at $3 \mathrm{mg} / \mathrm{kg} / \mathrm{d}$, was well tolerated (Martino et al 2005).

For invasive candidiasis, the role of polyenes has markedly diminished with the availability of better-tolerated echinocandins and the newer azoles. Echinocandins have good efficacy against fluconazole-susceptible and fluconazole-resistant candidal species; the newer azoles, voriconazole and posaconazole, have good activity against fluconazole-susceptible candidal species and fluconazole-resistant C.krusei, but their activity against fluconazole-resistant C. glabrata is suboptimal.

\section{Invasive aspergillosis (IA)}

A prospective, randomized trial (of 277 patients) published in 2002 demonstrated voriconazole to be superior in efficacy and survival to AmB deoxycholate $(1-1.5 \mathrm{mg} / \mathrm{kg} / \mathrm{d})$ in the therapy of invasive aspergillosis (Herbrecht et al 2002). Response rates of voriconazole and $\mathrm{AmB}$ in the overall study population were $52.8 \%$ and $31.6 \%$, respectively. Of interest, in the allogeneic stem cell group, the response rates were much lower for both drugs $(32.7 \%$ for voriconazole and $13.2 \%$ for AmB). Since this landmark study, voriconazole has been accepted as the initial choice of therapy; however, it is noteworthy that the trial did not use a lipid form of AmB as a comparator and most patients in the $\mathrm{AmB}$ deoxycholate arm had to stop therapy due to drug intolerance. Availability of oral and intravenous formulations and good tolerability profile make voriconazole an attractive agent; however, the drug may not be an optimal choice in all situations. For example, patients with breakthrough infection while on mold-active azole prophylaxis, patients with serious hepatic impairment, patients with serious cardiac risk factors (eg, QT interval prolongation) and patients with possible concomitant

Table 2 Clinical response to treatment with ABLC in patients with candidiasis, by prior treatment status

\begin{tabular}{|c|c|c|c|c|c|c|c|c|}
\hline \multirow[b]{2}{*}{$\begin{array}{l}\text { Type } \\
\text { of infection }\end{array}$} & \multicolumn{2}{|l|}{ Refractory } & \multicolumn{2}{|c|}{ Underlying renal disease } & \multirow[b]{2}{*}{$\begin{array}{l}\text { Intolerant } \\
\text { of prior } \\
\text { antifungal } \\
\text { therapy }\end{array}$} & \multirow[b]{2}{*}{$\begin{array}{l}\text { No prior } \\
\text { antifungal } \\
\text { therapy/ no } \\
\text { underlying } \\
\text { renal disease }\end{array}$} & \multirow[b]{2}{*}{$\begin{array}{l}\text { First-line } \\
\text { therapy } \\
\text { with ABLCa }\end{array}$} & \multirow[b]{2}{*}{$\begin{array}{l}\text { Second-line } \\
\text { therapy } \\
\text { with ABLC }\end{array}$} \\
\hline & $\begin{array}{l}\text { To all prior } \\
\text { antifungal } \\
\text { therapy }\end{array}$ & $\begin{array}{l}\text { To prior } \\
\text { azole }\end{array}$ & $\begin{array}{l}\text { With prior } \\
\text { antifungal } \\
\text { therapy }\end{array}$ & $\begin{array}{l}\text { With } \\
\text { no prior } \\
\text { antifungal } \\
\text { therapy }\end{array}$ & & & & \\
\hline $\begin{array}{l}\text { C. albicans } \\
(\mathrm{n}=364)\end{array}$ & $93 / 139(67)$ & $67 / 104(64)$ & $7 / 12(58)$ & $65 / 115(57)$ & $28 / 50(56)$ & $29 / 43(67)$ & $94 / 158(60)$ & $|28 / 20|(64)$ \\
\hline $\begin{array}{l}\text { Non-albicans } \\
\text { Candida species } \\
(n=375)\end{array}$ & $105 / 174(60)$ & $77 / 125(62)$ & II/I4 (79) & $57 / 96(59)$ & $27 / 52(52)$ & $28 / 34(82)$ & $85 / 130(65)$ & $143 / 240(60)$ \\
\hline $\begin{array}{l}\text { C. albicans + } \\
\text { non-albicans } \\
\text { Candida species } \\
(\mathrm{n}=90)\end{array}$ & $29 / 44(66)$ & $23 / 53(66)$ & $2 / 2(100)$ & $12 / 19(63)$ & $6 / 9(67)$ & $9 / 16(56)$ & $21 / 35(60)$ & $37 / 55(67)$ \\
\hline $\begin{array}{l}\text { Multiple } \\
\text { non-albicans } \\
\text { Candida species } \\
(\mathrm{n}=25)\end{array}$ & $8 / 15(53)$ & 6/II (55) & $1 / 2(50)$ & $0 / 2(0)$ & I/3 (33) & $0 / 2(0)$ & $0 / 4(0)$ & $0 / 20(50)$ \\
\hline Total & $235 / 372(63)$ & I73/293 (59) & $21 / 30(70)$ & I34/232 (58) & $62 / 114(54)$ & $66 / 95(70)$ & $200 / 327(6 I)$ & $318 / 516(62)$ \\
\hline
\end{tabular}

Reproduced with permission from Ito Jl, Hooshmand-Rad R. 2005. Treatment of Candida infections with amphotericin B lipid complex. Clin Infect Dis, 40(Suppl 6):S384-9I. Copyright (C) 2005. University of Chicago Press. All rights reserved.

Abbreviation: ABLC, amphotericin B lipid complex. 
zygomycosis are not good candidates for voriconazole. Also, in voriconazole-intolerant or voriconazole-failed cases of IA, a polyene or an echinocandin must be considered.

The CLEAR registry assessed 398 patients with IA receiving ABLC (median dose $4.8 \mathrm{mg} / \mathrm{kg} / \mathrm{d}$ ) (Chandrasekar and Ito 2005). Common underlying conditions were: hematopoietic stem cell transplantaion (25\%), hematologic malignancy $25 \%$; and solid organ transplantation $27 \%$. Failure of prior antifungal therapy (mostly AmB deoxycholate) was the primary reason for study enrollment. Cure or improved response was seen in $44 \%$ patients and a stable response in additional $21 \%$ patients (Table 3 ). No antagonism was observed when ABLC was administered after itraconazole exposure. When therapy with ABLC was added to itraconazole, the response rate was low $(27 \%)$, indicating the possibility of maximizing therapy in desperately ill patients. A $37 \%$ response rate was seen in 19 patients infected with Aspergillus terreus, an innately polyene-resistant species. As expected, response rate (cured + improved) with ABLC in those intolerant of $\mathrm{AmB}$ (54\%) was better compared with those receiving ABLC after failure of prior therapy (39\%). Similar response rates were seen in patients receiving ABLC as first-line or second-line treatment (intolerant of or refractory to prior therapy). Recognizing the fact that the CLEAR database and the study comparing voriconazole to AmB deoxycholate have large differences, the response rates for ABLC and voriconazole were similar.

The response rate with ABLC therapy in hematopoietic stem cell recipients $(n=85)$ with ABLC was the lowest (7\%-40\%) in single-site and multiple-site infections among different groups (Ito et al 2005). Response rate was 31\% (26 of 85 patients) overall, and $21 \%$ (5 of 24 ) in those with graft versus host disease. When ABLC was administered as first-line therapy, the response rate was slightly improved (41\%), perhaps implying earlier therapy may have a better outcome. This compares favorably to the $31 \%$ response rate of voriconazole among allogeneic stem cell recipients in the Herbrecht study. Serum creatinine doubled in $12 \%$ patients (10 of 85 ) and $2 \%$ required dialysis.

In the emergency-use study, $42 \%$ had complete or partial response with ABLC for invasive aspergillosis $(n=130)$ (Walsh et al 1998). Response in single organ extrapulmonary aspergillosis was better than that with cases of disseminated aspergillosis.

Voriconazole is useful as primary therapy for invasive aspergillosis while posaconazole may be considered for salvage therapy (approved in Europe). Itraconazole, given its drug interaction profile and suboptimal bioavailability, is no longer an attractive agent. Among echinocandins, caspofungin is approved for use in salvage therapy; data on primary therapy are not available. Thus, the role of polyene therapy in IA, as in candidiasis, has diminished. Among combination drug therapy strategies, a newer azole (eg, voriconazole) plus an echinocandin, based on in vitro and animal data, is currently favored.

\section{Zygomycosis}

Zygomycosis is a serious infection of increasing frequency, particularly in compromised hosts (Kontoyiannis et al 2005; Roden et al 2005). Among the newer azoles, voriconazole has no activity against zygomycetes, while oral posaconazole has been studied in the salvage setting in a limited number of patients $(\mathrm{n}=91)$ with a favorable outcome $(60 \%$ complete or partial response at 12 weeks, with $21 \%$ stable response), particularly in the setting of surgical debridement

Table 3 Clinical response to treatment with ABLC in patients with proven invasive aspergillosis by prior treatment status

\begin{tabular}{|c|c|c|c|c|c|c|c|c|}
\hline \multirow[b]{2}{*}{$\begin{array}{l}\text { Clinical } \\
\text { response }\end{array}$} & \multirow[b]{2}{*}{$\begin{array}{l}\text { Unknown } \\
(n=I I)\end{array}$} & \multicolumn{2}{|c|}{ Second-line therapy with ABLC } & \multirow[b]{2}{*}{$\begin{array}{l}\text { Intolerant } \\
\text { of prior } \\
\text { antifungal } \\
\text { therapy } \\
(n=50)\end{array}$} & \multicolumn{2}{|c|}{ First-line therapy with ABLC } & \multirow[b]{2}{*}{$\begin{array}{l}\text { Other } \\
(n=2)\end{array}$} & \multirow[b]{2}{*}{$\begin{array}{l}\text { Total } \\
(n=368)\end{array}$} \\
\hline & & $\begin{array}{l}\text { Refractory } \\
\text { to prior } \\
\text { antifungal } \\
\text { therapy } \\
(n=157)\end{array}$ & $\begin{array}{l}\text { Underlying } \\
\text { renal disease/ } \\
\text { prior antifungal } \\
\text { therapy }(n=9)\end{array}$ & & $\begin{array}{l}\text { Underlying } \\
\text { renal disease } \\
\text { no prior } \\
\text { antifungal } \\
\text { therapy } \\
(\mathrm{n}=\mathbf{8 8})\end{array}$ & $\begin{array}{l}\text { No prior } \\
\text { antifungal } \\
\text { therapyl } \\
\text { no renal } \\
\text { disease } \\
(n=5 I)\end{array}$ & & \\
\hline Cured & - & $15(10)$ & - & $4(8)$ & $16(18)$ & $6(12)$ & $\mathrm{I}(50)$ & $42(\mathrm{II})$ \\
\hline Improved & $2(18)$ & $45(29)$ & $7(78)$ & $23(46)$ & $30(34)$ & $13(26)$ & - & $120(33)$ \\
\hline Stable & $2(18)$ & $33(2 I)$ & I (II) & $12(24)$ & $20(23)$ & $10(20)$ & - & $78(21)$ \\
\hline Deteriorated & $7(64)$ & $64(4 I)$ & I (II) & II (22) & $22(25)$ & $22(43)$ & I (50) & $128(35)$ \\
\hline
\end{tabular}

Note: Data are no. (\%) of patients.

From Chandrasekar and Ito (2005).

Abbreviation: ABLC, amphotericin B lipid complex. 
and improvement of underlying immune deficit (van Burik et al 2006).

In the CLEAR database $(n=64)$, a median daily dose of $4.8 \mathrm{mg} / \mathrm{kg}$ ABLC resulted in cure or improvement in $52 \%$ and in stable disease in $20 \%$ of patients (Larkin and Montero 2003). With ABLC as second-line therapy $(n=35)$, response rates in those refractory to prior therapy and those intolerant of prior therapy were $48 \%$ ( 11 of 23 patients) and 58\% ( 7 of 12 patients) respectively. As expected, surgical debridement was performed in most patients.

Therapy with a lipid form of AmB (at 5-10 mg/kg/d) is the currently accepted approach for zygomycosis until more data with posaconazole become available. In current practice, after stabilization is achieved with polyene therapy, switching over to oral posaconazole (400 mg twice daily) is becoming common. Duration of therapy remains unclear, and is usually based on control of infection and correction of underlying immune deficit. Given the high frequency of nephrotoxicity with AmB deoxycholate, this formulation is no longer appropriate for zygomycosis.

\section{Cryptococcosis}

With the availability of antiretroviral therapy for the management of AIDS, the incidence of cryptococcosis has markedly declined. Cryptococcosis is one of the few fungal infections for which a polyene is still advocated as primary therapy. AmB deoxycholate $(0.7 \mathrm{mg} / \mathrm{kg} / \mathrm{d})$ plus flucytosine $(100 \mathrm{mg} / \mathrm{kg} / \mathrm{d})$ for an initial 2 weeks followed by fluconazole $(400 \mathrm{mg} / \mathrm{d})$ for an additional 8 weeks is widely accepted as the standard treatment (Saag et al 2000).

In the CLEAR database, 101 patients with cryptococcoccal infection were evaluable (Baddour et al 2005). Response rates (cured or improved) with ABLC were $65 \%$ (51 of 78 patients) for patients with central nervous system (CNS) involvement and 70\% (16 of 23) for those without CNS involvement. Response rates were $56 \%$ (19 of 34 patients) for patients who were refractory to prior antifungal therapy, and 65\% (11 of 17) for patients who were intolerant of prior fungal therapy. First-line therapy $(n=44)$ achieved a $75 \%$ response rate while second-line therapy $(n=56)$ had a $59 \%$ response rate. In the compassionate-use protocol, 11 patients were given ABLC (median dose $4.9 \mathrm{mg} / \mathrm{kg} / \mathrm{d}$ ) for cryptococcosis; these patients were refractory to or intolerant of $\mathrm{AmB}$ or had preexisting renal impairment (Walsh et al 1998). Seven of 11 had complete or partial response. In a study comparing ABLC $(5 \mathrm{mg} / \mathrm{kg} / \mathrm{d})$ and AmB deoxycholate $(0.7-1.2 \mathrm{mg} / \mathrm{kg} / \mathrm{d})$ for the treatment of patients with AIDS-associated cryptococcal meningitis, clinical response of $86 \%$ (18 of 21 patients) was observed with the former and 65\% (11 of 17 patients) with the latter (Sharkey et al 1996).

From the above body of data, it may be concluded that ABLC is an effective drug for the treatment of cryptococcal infection in patients with refractory to or intolerant of prior therapy with AmB deoxycholate. Also, ABLC appears at least as effective as AmB deoxycholate as initial therapy. Currently, azoles (including voriconazole and posaconazole) or echinocandins are not considered the drugs of choice for initial therapy of cryptococcosis.

\section{Fusariosis}

Fusariosis is an uncommon fungal infection. Usually it is seen in compromised patients with prolonged neutropenia or after cortiosteroid use for graft-versus host disease in allogeneic stem cell transplant patients. Often the infection presents with cutaneous lesions and positive blood cultures. The organism, in clinical laboratories, is not identified to the species level; some species are susceptible to AmB (not to voriconazole), while others may be susceptible only to voriconazole.

Salvage therapy with voriconazole yielded an overall response rate of $46 \%$ in patients with invasive fusariosis (Perfect et al 2003). In the CLEAR database, ABLC was administered as first-line therapy to 8 of $28(29 \%)$ patients and as second-line treatment to 20 of $28(71 \%)$ patients; most had infection refractory to prior antifungals (43\%) or demonstrated intolerance of prior antifungals $(29 \%)$ (Perfect 2005). ABLC was administered at a median dose of $4.5 \mathrm{mg} / \mathrm{kg} / \mathrm{d}$ for a median duration of 20.5 days. Of the 26 evaluable patients, 12 (46\%) were cured or improved, and $3(12 \%)$ were stabilized after ABLC therapy. Patients with normal absolute neutrophil counts (ANC $\geq 500$ cells $/ \mathrm{mm}^{3}$ ) at the end of therapy had better outcomes than those who did not, regardless of neutrophil count at baseline. Median serum creatinine levels were $1.15 \mathrm{mg} / \mathrm{dL}$ and $1.40 \mathrm{mg} / \mathrm{dL}$ at the start and end of therapy, respectively. In the compassionate-use protocol, 9 of 11 of patients with fusariosis had a complete or partial response with ABLC (Walsh et al 1998).

\section{Histoplasmosis}

Polyenes and itraconazole are the drugs of choice for the treatment of histoplasmosis. Clinical response rate with itraconazole or liposomal AmB is excellent (85\%); however, for patients with positive blood culture, more rapid clearance was achieved with liposomal amphotercin B (Wheat et al 2001). When liposomal AmB at $3 \mathrm{mg} / \mathrm{kg} / \mathrm{d}$ was compared with $\mathrm{AmB}$ deoxycholate at $0.7 \mathrm{mg} / \mathrm{kg} / \mathrm{d}$ for therapy of disseminated histoplasmosis in AIDS patients $(n=81)$, 
the former had improved success and higher survival rate (Johnson et al 2002).

In the CLEAR database, 21 of 25 patients (84\%) with histoplasmosis had complete or partial response with ABLC therapy (Perfect 2005). In patients with severe or lifethreatening histoplasmosis, therapy with a polyene drug is preferred to an azole.

\section{Other molds}

In the CLEAR database, patients with 59 other mold infections were assessed (Perfect 2005). Pathogenic fungi were Blastomyces sp $(n=17)$, Coccidioides $\mathrm{sp}(\mathrm{n}=8)$ and Scedosporium $(\mathrm{n}=11)$. Median daily dose of ABLC was $4 \mathrm{mg} / \mathrm{kg} / \mathrm{d}$ and the median duration of therapy was 14 days. Cured or improved responses were seen in: blastomycosis - 9 of 14 patients; coccidioidomycosis -5 of 8 patients and scedosporiosis -1 of 8 patients. Responses in other infections were: Acremoniun (2 of 4 patients), Curvularia (3 of 4 patients), Alternaria (3 of 3 patients), Scopulariopsis (0 of 3 patients), Trichoderma (2 of 2 patients), Dactylaria (1 of 2 patients), Exophiala (1 of 2 patients), Bipolaris (1 of 1 patient), Phoma and Paecilomyces (0 of 2 patients).

\section{Special populations} Children

Limited data are available for antifungal therapy in pediatric patients (Herbrecht et al 2001). In the CLEAR registry, 548 children and adolescents were enrolled to receive ABLC therapy (Wiley et al 205). Most were either intolerant of or refractory to conventional antifungal therapy. All had cancer, or had received a bone marrow, cord blood, or solid organ transplant and then received ABLC for documented or suspected invasive fungal infection. A complete or partial response was seen in 55\% patients with an additional $17 \%$ with a stable outcome (Table 4). The drug was well tolerated with modest renal impairment; it is noteworthy that $72 \%$ study patients had received 1 or more concomitant nephrotoxins.

A subset analysis of the compassionate-use study demonstrated the efficacy and safety of ABLC in 111 pediatric patients aged 21 days to 16 years (Walsh et al 1998). Seventy (38 of 54 patients) had complete or partial response, and no significant changes in serum creatinine levels occurred from baseline to end of therapy. In a limited retrospective study of 46 pediatric patients (mean age $10 \pm 5$ years) with invasive fungal infection and refractory to or intolerant of prior antifungal therapy, therapy with ABLC had response rates of $89 \%$ for systemic candidiasis (17 of 19 patients) and $78 \%$ for invasive aspergillosis (18 of 23 patients) (Herbrecht et al 2001). The drug, given at a mean daily dose of $4.1 \mathrm{mg} / \mathrm{kg} / \mathrm{d}$ for a mean duration of 39 days, was well tolerated.

In neonates with invasive canididiasis, ABLC was well tolerated and effective both as first-line therapy and in those who failed to respond to prior systemic antifungal treatment or had drug-associated nephrotoxicity and/or underlying renal disease (Adler-Shohet et al 2001).

\section{Elderly}

From the CLEAR database, Hooshmand-Rad et al (2005) published their analysis of 572 elderly patients who received ABLC for proven or suspected invasive fungal infection. Clinical response was $56 \%$ in those $>65$ years of age $(n=572)$ and $51 \%$ in those $<65$ years of age $(n=2930)$ $(\mathrm{p}=0.049)$. Despite higher pretreatment serum creatinine values in the elderly $(1.7 \mathrm{mg} / \mathrm{dL}$ vs $1.4 \mathrm{mg} / \mathrm{dL})$, both groups showed only a $0.1 \mathrm{mg} / \mathrm{dL}$ rise in median serum creatinine level from baseline to end of therapy $(p=0.54)$.

\section{Solid organ transplant recipients}

Linden et al (2000) reviewed open-label, second-line treatment studies of ABLC for severe life-threatening invasive fungal

Table 4 Clinical response to treatment with ABLC, according to age, in evaluable patients with documented fungal infection ( $\mathrm{N}=255)$

\begin{tabular}{|c|c|c|c|c|c|}
\hline Clinical response & All $(n=255)$ & $0-3 \mathrm{mo}(\mathrm{n}=32)$ & 4 mo-l yr $(n=19)$ & $2-I I$ yr $(n=87)$ & $\mid 2-20$ yr $(n=|| 7)$ \\
\hline Cured & $74(29.0)^{*}$ & $19(59.4)$ & $6(31.6)$ & $23(26.4)$ & $26(22.2)$ \\
\hline Improved & $65(25.5)$ & $4(12.5)$ & $6(31.6)$ & $24(27.6)$ & $31(26.5)$ \\
\hline Stable & $43(16.9)$ & $3(9.4)$ & $5(26.3)$ & $19(21.8)$ & $16(13.7)$ \\
\hline Deteriorated & $73(28.6)$ & $6(18.8)$ & $2(10.5)$ & $21(24.1)$ & $44(37.6)$ \\
\hline Cured + improved & $139(54.5)$ & $23(71.9)$ & $12(63.2)$ & $47(54.0)$ & $57(48.7)$ \\
\hline $\begin{array}{l}\text { Cured }+ \text { improved }+ \\
\text { stable }\end{array}$ & I82 (7I.4) & $26(81.3)$ & $17(89.5)$ & $66(75.9)$ & $73(62.4)$ \\
\hline
\end{tabular}

$*(\%)$

Reproduced with permission from Wiley JM, Seibel NL, Walsh TJ. 2005. Efficacy and safety of amphotericin B lipid complex in 548 children and adolescents with invasive fungal infections. Pediatr Infect Dis J, 24:167-I74. (C) Lippincott Williams \& Wilkins.

Abbreviation: ABLC, amphotericin B lipid complex. 
infections in solid organ recipients who were refractory to or intolerant of prior antifungal therapy (mostly AmB deoxycholate) or had pre-existing renal disease. There were 79 solid organ transplant recipients (heart-25; liver-20; kidney-17; lung-11; pancreas-1; multiple-5) who received ABLC (median dose $4.6 \mathrm{mg} / \mathrm{kg} / \mathrm{d}$ ) for a median duriation of 28 days for the following infections: aspergillosis $(n=39)$, candidiasis $(n=20)$; zygomycosis $(n=8)$; cryptococcosis and histoplasmosis ( $\mathrm{n}=3$ each); and blastomycosis, cladosporiosis, fusariosis, and infection due to Bipolaris hawaiiensis, Dactylaria gallopova, and an unspecified fungus ( $\mathrm{n}=1 \mathrm{each}$ ). In the 67 evaluable patients, response rate was 58\%. Response rates for candidiasis and aspergillosis were $47 \%$ and $71 \%$, respectively. Mean baseline serum creatinine was $3.2 \mathrm{mg} / \mathrm{dL}$; 64 patients $(81 \%)$ had stable $(n=37)$ or improved $(n=27)$ serum creatinine at the end of therapy.

\section{Stem cell recipients}

Both emergency-use study (59 patients) and the CLEAR database ( $>800$ patients) included stem cell recipients with invasive fungal infection. Among the 59 patients, 31 (53\%) responded to ABLC treatment. Improvement in serum creatinine was noted at weeks 1 to 3 and 6 (Wingard 1997). In the CLEAR registry, response rates with ABLC among stem cell recipients were $40 \%$ for invasive candidiasis, $40 \%$ for invasive aspergillosis (single site infection), and 13\% (1 of 8 patients) for invasive fusariosis.

\section{Safety}

Lipid-based formulations of AmB cause less nephrotoxicity and hypokalemia than AmB deoxycholate (Barrett et al 2003).

Walsh et al (1998) reported that ABLC therapy was associated with a significant improvement in renal function, particularly among those with pre-existing renal insufficiency or nephrotoxicity caused by AmB deoxycholate. Serum creatinine levels decreased from baseline during the course of ABLC therapy ( $\mathrm{p} \leq 0.02$ ), and renal function improved from week 1 to week 6 ( $\mathrm{p}<0.0003$ ) in 162 patients with serum creatinine values $\geq 2.5 \mathrm{mg} / \mathrm{dL}$ on baseline. Table 5 shows the CLEAR data for change in renal function in 3514 ABLC-treated patients (Alexander and Wingard 2005). Serum creatinine values doubled in $13 \%$ of patients, and new dialysis was needed in $3 \%$ of patients. Risk factors identified for nephrotoxicity were concomitant treatment with potentially nephrotoxic agents and a baseline serum creatinine value of $<2 \mathrm{mg} / \mathrm{dL}$. In allogeneic stem cell recipients, $17 \%$ demonstrated end-of-therapy doubling of serum creatinine levels. In the pediatric population, there were few clinically significant deleterious effects on renal function (Wiley et al 2005). There was no significant difference between the rate of new hemodialysis versus baseline hemodialysis. Whether rates of nephrotoxicity vary between ABLC and liposomal AmB remains controversial. While several studies have suggested that the rates of nephrotoxicity are similar, Wingard et al reported that the baseline creatinine values doubled after 2 weeks in $14.8 \%$ (12 of 81 patients) of patients receiving liposomal AmB, and in 42.3\% (33 of 78 patients) receiving ABLC (Cannon et al 2001; Fleming et al 2001; Wingard et al 2000). Preliminary data of a recent meta-analysis suggested that the rates are similar (Safdar et al 2007).

Transient infusion-related events include fever, chills, nausea, and vomiting; most abate within a few days of initiation of $\mathrm{ABLC}$, and often are managed with premedication. Such infusion-related effects appear to be less with liposomal AmB. Other adverse events with ABLC include hepatotoxicity, hyperkalemia, hypertension, and pulmonary reactions.

\section{Are AmB and lipid forms of AmB obsolete?}

Despite serious nephrotoxic potential, AmB deoxycholate and lipid forms of AmB have long enjoyed clinical use, primarily because other systemic antifungal drugs have been lacking. Arrival of newer triazoles and echinocandins in the past few years has changed the situation; because of their safety and efficacy profiles, these drugs are steadily edging out polyenes from clinical practice. Nevertheless, AmB has a long track record, possesses a broad spectrum of antifungal activity, and remains useful particularly in the setting of critically ill patients with invasive fungal disease where the etiologic pathogen is not identified. Moreover, resistance to AmB has remained rare despite decades of its use, while in contrast, several reports of resistance to azoles and/or echinocandins among yeasts and molds have already emerged.

Table 6 lists the potential clinical situations where AmB deoxycholate or the lipid forms of $\mathrm{AmB}$ continue to serve as useful drugs in clinical practice. With zygomycosis, until more data become available with posaconazole, the polyenes remain the primary drugs for initial therapy. As higher doses are generally favored, lipid forms of AmB are preferred to $\mathrm{AmB}$ deoxycholate to minimize nephrotoxicity. Likewise, in the management of serious cryptococcosis (eg, cryptococcal meningitis, disseminated cryptococosis), a polyene drug in combination with flucytosine is recommended; azoles (ie, fluconazole) may be useful in maintenance therapy while echinocandins have no reliable activity against cryptococcus. 
Table 5 Renal function in ABLC-treated patients with fungal infections

\begin{tabular}{|c|c|c|c|c|c|c|c|c|c|}
\hline \multirow[b]{2}{*}{ Patient group } & \multicolumn{9}{|c|}{ End-of-therapy renal function parameter } \\
\hline & $\begin{array}{l}\text { Baseline S-Cr } \\
\text { level, median } \\
\text { (range), Mg/dL }\end{array}$ & $\begin{array}{l}\text { Change in } \mathrm{C}_{\mathrm{Cr}} \\
\text { median (range), } \\
\mathrm{mL} / \mathrm{min}\end{array}$ & $\mathbf{p}$ & $\begin{array}{l}\text { Doubling of } \\
\text { baseline S-Cr } \\
\text { level No. (\%) } \\
\text { of patients }\end{array}$ & $\mathbf{p}$ & $\begin{array}{l}\text { Increase in } \\
\mathrm{S}-\mathrm{Cr} \text { level To } \\
\geq 2.5 \mathrm{mg} / \mathrm{dL} \\
\text { No. (\%) of } \\
\text { patients }\end{array}$ & $\mathbf{p}$ & $\begin{array}{l}\text { New } \\
\text { dialysis } \\
\text { No. (\%) of } \\
\text { patients }\end{array}$ & $\mathbf{p}$ \\
\hline All patients $(\mathrm{N}=3514)$ & $1.4(0.08-6)$ & $-3(-119$ to 118$)$ & - & $468(13)$ & - & $412(12)$ & - & $92(3)$ & - \\
\hline \multicolumn{10}{|l|}{ Age group } \\
\hline $\begin{array}{l}<18 \text { years } \\
(n-454)\end{array}$ & $0.7(0.1-6)$ & $0(-105$ to 108$)$ & - & $71(16)$ & - & $27(6)$ & - & $12(3)$ & - \\
\hline$\geq 18$ years $(n=3048)$ & $1.6(0.08-6)$ & $-3(-119$ to 118$)$ & 0.008 & $396(13)$ & 0.110 & $385(13)$ & $<0.001$ & $80(3)$ & 0.975 \\
\hline \multicolumn{10}{|l|}{$\begin{array}{l}\text { Status prior to start of } \\
A B L C \text { therapy }\end{array}$} \\
\hline $\begin{array}{l}\text { Refractory } \\
(n=14 I I)\end{array}$ & $1.2(0.08-6)$ & -5 (-III to 99) & 0.033 & $220(16)$ & 0.282 & $157(\mathrm{II})$ & 0.397 & $25(2)$ & 0.209 \\
\hline $\begin{array}{l}\text { Underlying renal } \\
\text { disease, prior antifungal } \\
\text { therapy }(\mathrm{n}=84)\end{array}$ & $2(0.3-6)$ & $0.5(-107$ to 52$)$ & $<0.001$ & II (I3) & 0.307 & $14(17)$ & 0.056 & $4(5)$ & 0.027 \\
\hline $\begin{array}{l}\text { Underlying renal } \\
\text { disease, no prior } \\
\text { antifungal therapy } \\
(n=945)\end{array}$ & $2(0.15-6)$ & $0(-99$ to 118$)$ & $<0.001$ & $83(9)$ & $<0.009$ & $133(14)$ & 0.025 & $44(5)$ & $<0.001$ \\
\hline Intolerance ${ }^{c}(n=573)$ & $1.4(0.2-6)$ & $0(-108$ to 101$)$ & $<0.001$ & $60(11)$ & $<0.00$ I & $54(9)$ & 0.855 & $14(2)$ & 0.072 \\
\hline $\begin{array}{l}\text { No prior antifungal } \\
\text { therapy/no renal } \\
\text { disease }(n=43 \mathrm{I}) \\
\text { Prior treatment }\end{array}$ & $I(0.1-6)$ & $-10(-117$ to 101$)$ & - & $77(18)$ & - & $42(10)$ & - & $4(1)$ & - \\
\hline $\begin{array}{l}\text { No prior Amb } \\
(\mathrm{n}=2056)\end{array}$ & $1.3(0.08-6)$ & $-5(-119$ to II8) & $<0.001$ & $311(15)$ & $<0.001$ & $230(11)$ & 0.290 & $50(2)$ & 0.408 \\
\hline Prior AmB $(n=1398)$ & $1.6(0.19-6)$ & $0(-1 \mid 7$ to $10 \mathrm{I})$ & - & $146(10)$ & - & $173(12)$ & - & $40(3)$ & $\ldots$ \\
\hline
\end{tabular}

Note: Statistical analysis was performed by using the median scores test for continuous variables and $\chi^{2}$ or Fisher's exact test, as appropriate, for categorical variables.

Abbreviations: $\mathrm{AmB}$, amphotericin B deoxycholate; $\mathrm{C}_{\mathrm{Cr}}$, predicted creatinine clearance; $\mathrm{S}-\mathrm{Cr}$, serum creatinine.

a $\mathrm{P}$ values in this subsection compare each category with patients in the "no prior antifungal medication/no underlying renal disease" category.

${ }^{\text {'}} 22 \%$ of these patients also had underlying renal disease.

Intolerance included infusion-related toxicity, increasing S-Cr level, or hepatotoxicity.

Reproduced from Alexander BD,Wingard JR. 2005. Study of renal safety in amphotericin B lipid complex-treated patients. Clin Infect Dis, 40(Suppl 6):S4I4-S2I.Copyright @) 2005. University of Chicago Press. All rights reserved.

Table 6 Amphotericin B - clinical indications

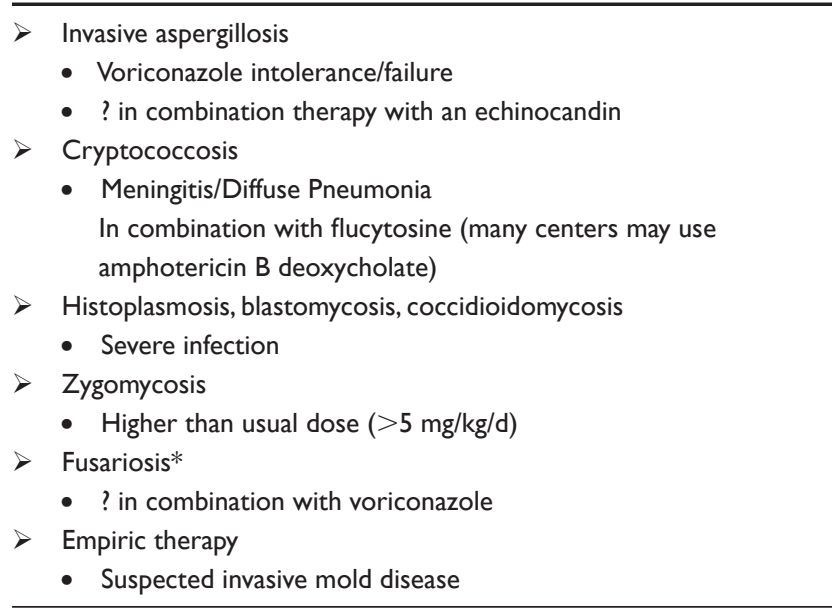

*Different species of fusarium vary in their susceptibility to amphotericin B and voriconazole, and most laboratories do not identify the pathogen to the species level.
Serious endemic mycoses warrant initial therapy with a polyene drug. For therapy of fusariosis, a polyene drug and/or voriconazole is recommended for initial therapy, since the different species have variable susceptibility, and most hospital laboratories do not identify this organism to the species level nor perform susceptibility studies. Although voriconazole has become the drug of choice for invasive aspergillosis, refractoriness or intolerance to the drug may be encountered; in such cases, a lipid form of AmB serves as an effective alternative. Finally, given its broad spectrum of activity, AmB remains useful as empiric therapy when an invasive mold infection particularly zygomycosis, is strongly suspected. In general, lipid forms of $\mathrm{AmB}$ are preferred to $\mathrm{AmB}$ deoxycholate in the aforementioned situations in view of the reduced 
nephrotoxic potential of the former. It is worth emphasizing that superiority in efficacy of the lipid forms of AmB over the deoxycholate formulation has not been established.

In children and neonates, AmB is remarkably well tolerated without significant nephrotoxicity, hence use of the polyene may continue in this population. Finally, in resourcepoor countries, since AmB deoxycholate is likely to be much less expensive than the newer drugs including the lipid forms of $\mathrm{AmB}$, the polyene may remain an important drug in their antifungal drug armamentarium.

\section{Conclusion}

AmB lipid complex (ABLC) is an effective and safe drug in the treatment of invasive fungal infections caused by yeasts and molds in many diverse compromised patient populations. ABLC causes nephrotoxicity particularly when used along with other nephrotoxic drugs, but it is much less toxic than AmB deoxycholate formulation. Its efficacy is well established in patients with infection refractory to AmB deoxycholate or in patients who are intolerant of the same formulation. The drug has not been rigorously evaluated for use as primary therapy. Its role in current clinical practice is markedly curtailed, largely due to the recent availability of effective and better tolerated newer triazoles and echinocandins. However, concerns with the newer agents such as limited spectrum of activity, emergence of drug-resistant fungi and significant drug-drug interactions assure the continued clinical use of the polyene class of drugs.

\section{Disclosures}

The author reports no conflicts of interest.

\section{References}

Adedoyin A, Bernardo JF, Swenson CE et al. 1997. Pharmacokinetic profile of Abelcet (amphotericin B lipid complex injection): combined experience from phase I and phase II studies. Antimicrob Agents Chemother, 41:2201-8.

Adler-Shohet FC, Arrieta AC, Ross LA et al. 2001. Amphotericin B lipid complex in neonates with invasive candidiasis. Clin Infect Dis, 33:1198.

Alexander BD, Wingard JR. 2005. Study of renal safety in amphotericin B lipid complex-treated patients. Clin Infect Dis, 40(Suppl 6):S414-S21.

Baddour LM, Perfect JR, Ostrosky-Zeichner L. 2005. Successful use of amphotericin B lipid complex in the treatment of cryptococcosis. Clin Infect Dis, 40 (Suppl 6):S409-S13.

Barrett JP, Vardulaki KA, Conlon C, et al. 2003. A systematic review of the antifungal effectiveness and tolerability of amphotericin B formulations. Clin Ther, 25:1295-320.

Cannon JP, Garey KW, Danziger LH. 2001. A prospective and retrospective analysis of the nephrotoxicity and efficacy of lipid-based amphotericin B formulations. Pharmacother, 21:1107-14.

Chamilos G, Luna M, Lewis RE, et al. 2006. Invasive fungal infections in patients with hematologic malignancies in a tertiary care cancer center: an autopsy study over a 15-year period (1989-2003). Haematologica, 91:986-9.
Chandrasekar PH, Ito JI. 2005. Amphotericin B lipid complex in the management of invasive aspergillosis in immunocompromised patients. Clin Infect Dis, 40(Suppl 6):S392-S400.

Fleming RV, Kantarjian HM, Husni R, et al. 2001. Comparison of amphotericin B lipid complex (ABLC) vs. AmBisome in the treatment of suspected or documented fungal infections in patients with leukemia. Leukemia Lymphoma, 40:511-20.

Gilgado F, Serena C, Cano J, et al. 2006. Antifungal susceptibilities of the species of the Pseudallescheria boydii complex. Antimicrob Agents Chemother, 50:4211-13.

Hawkins JL, Baddour LM. 2003. Candida lusitaniae infections in the era of fluconazole availability. Clin Infect Dis, 36:e14-e18.

Herbrecht R, Auvrignon A, Andres E, et al. 2001. Efficacy of amphotericin B lipid complex in the treatment of invasive fungal infections in immunosuppressed paediatric patients. Eur J Clin Microbiol Infect Dis, 20:77-82.

Herbrecht R, Denning DW, Patterson TF, et al. 2002. Voriconazole versus amphotericin B for primary therapy of invasive aspergillosis. $N$ Engl J Med, 347:408-15.

Hooshmand-Rad R, Chu A, Gotz V, et al. 2005. Use of amphotericin B lipid complex in elderly patients. $J$ Infect, 50:277-87.

Ito JI, Chandrasekar PH, Hooshmand-Rad R. 2005. Effectiveness of amphotericin B lipid complex (ABLC) treatment in allogeneic hematopoietic cell transplant (HCT) recipients with invasive aspergillosis (IA). Bone Marrow Transplant, 36:873-7.

Ito JI, Hooshmand-Rad R. 2005. Treatment of Candida infections with amphotericin B lipid complex. Clin Infect Dis, 40(Suppl 6):S384-91.

Janoff AS, Perkins WR, Saletan SI, et al. 1993. Amphotericin B lipid complex (ABLC ): a molecular rationale for the attenuation of amphotericin B related toxicities. J Liposomes Res, 3:451-71.

Johnson PC, Wheat LI, Cloud GA, et al. 2002. Safety and efficacy of liposomal amphotericin B compared with conventional amphotericin B for induction therapy of histoplasmosis in patients with AIDS. Ann Intern Med, 137:105-9.

Kontoyiannis DP, Lionakis MS, Lewis RE, et al. 2005. Zygomycosis in a tertiary care cancer center in the era of Aspergillus-active antifungal therapy: a case-controled observational study of 27 recent cases. J Infect Dis, 191:1350-9.

Larkin JA, Montero JA. 2003. Efficacy and safety of amphotericin B lipid complex for zygomycosis. Infect Med, 20:201-6.

Lewis RE, Liao G, Hou J, et al. 2007. Comparative analysis of amphotericin B lipid complex and liposomal amphotericin B kinetics of lung accumulation and fungal clearance in a murine model of acute invasive pulmonary aspergillosis. Antimicrob Agents Chemother, 51:1253-58.

Linden P, Williams P and Chan KM. 2000. Efficacy and safety of amphotericin $\mathrm{B}$ lipid complex in injection (ABLC) in solid-organ transplant recipients with invasive fungal infections. Clin Transplant, 14:329-39.

Martin GS, Mannino DM, Eaton S, et al. 2003. The epidemiology of sepsis in the United States from 1979 through 2000. N Engl J Med, 348:1546-54.

Martino R. 2004. Efficacy, safety and cost-effectiveness of amphotericin B lipid complex (ABLC): a review of the literature. Curr Med Res Opin, 20:485-504.

Martino R, Cortes M, Subira M, et al. 2005. Efficacy and toxicity of intermediate dose amphotericin B lipid complex as a primary or salvage treatment of fungal infections in patients with hematologic malignancies. Leuk Lymphoma, 46:1429-35.

Ostrosky-Zeichner L, Pappas PG. 2006. Invasive candidiasis in the intensive care unit. Crit Care Med, 34:857-62.

Pappas PG (ed). 2005. Amphotericin B lipid complex in the treatment of invasive fungal infections: results of the Collaborative Exchange of Antifungal Research (CLEAR), an industry-supported patient registry. Clin Infect Dis, 40(Suppl 6):S379-S83.

Perfect JR. 2005. Treatment of non-aspergillus molds in immunocompromised patients with amphotericin B lipid complex. Clin Infect Dis, 40(Suppl 6): S401-S408. 
Perfect JR, Marr KA, Walsh TJ, et al. 2003. Voriconazole treatment for less-common, emerging, or refractory fungal infections. Clin Infect Dis, 36:1122-31.

Roden MM, Zaoutis TE, Buchanan WL, et al. 2005. Epidemiology and outcome of zygomycosis: a review of 929 reported cases. Clin Infect Dis, 41:634-53.

Saag MS, Graybill RJ, Larsen RA, et al. 2000. Practice guidelines for the management of cryptococcal disease. Infectious Diseases Society of America. Clin Infect Dis, 30:710-18.

Safdar A, Ma J, Walsh TJ, et al. 2007. Nephrotoxicity associated with amphotericin B (AmB) lipid complex (ABLC) vs. liposomal amphotericin $\mathrm{B}$ (L-AmB). 47th Interscience Conference on Antimicrobial Agents and Chemotherap, Abstract M-1168,pg 442.

Sharkey PK, Graybill JR, Johnson ES, et al. 1996. Amphotericin B lipid complex compared with amphotericin B in the treatment of cryptococcal meningitis in patients with AIDS. Clin Infect Dis, 22:315-21.

Sutton DA, Sanche SE, Revankar SG, et al. 1999. In vitro amphotericin B resistance in clinical isolates of Aspergillus terreus, with a head to head comparison to voriconazole. J Clin Microbiol, 37:2343-5. van Burik JA, Hare RS, Solomon HF, et al. 2006. Posaconazole is effective as salvage therapy in zygomycosis: a retrospective summary of 91 cases. Clin Infect Dis, 42:e61-e5.

Walsh TJ, Hiemenz JW, Seibel NL, et al. 1998. Amphotericin B lipid complex for invasive fungal infections: Analysis of safety and efficacy in 556 cases. Clin Infect Dis, 26:1383-96.

Wheat LI, Cloud G, Johnson PC, et al. 2001. Clearance of fungal burden during treatment of disseminated histoplasmosis with liposomal amphotericin B versus itraconazole. Antimicrob Agents Chemother, 45:2354-7.

Wiley JM, Seibel NL and Walsh TJ. 2005. Efficacy and safety of amphotericin B lipid complex in 548 children and adolescents with invasive fungal infections. Pediatr Infect Dis J, 24:167-74.

Wingard JR. 1997. Efficacy of amphotericin B lipid complex injection (ABLC) in bone marrow transplant recipients with life-threatening systemic mycoses. Bone Marrow Transplant, 19:343-7.

Wingard JR, White MH, Anaissie E, et al. 2000. A randomized, doubleblind comparative trial evaluating the safety of liposomal amphotericin B versus amphotericin B lipid complex in the empirical treatment of febrile neutropenia. Clin Infect Dis, 31:1155-63. 